\title{
Phenotypic characterization of murine models of cerebral cavernous malformations
}

\author{
Hussein A. Zeineddine ${ }^{1} \cdot$ Romuald Girard $^{1} \cdot$ Laleh Saadat $^{1} \cdot$ Le Shen $^{1,2} \cdot$ Rhonda Lightle $^{1} \cdot$ Thomas Moore $^{1}$. \\ Ying Cao ${ }^{1} \cdot$ Nick Hobson $^{1} \cdot$ Robert Shenkar $^{1} \cdot$ Kenneth Avner $^{1} \cdot$ Kiranj Chaudager $^{1} \cdot$ Janne Koskimäki $^{1}$. \\ Sean P. Polster ${ }^{1} \cdot$ Maged D. Fam ${ }^{1} \cdot$ Changbin Shi $^{1} \cdot$ Miguel Alejandro Lopez-Ramirez $^{3} \cdot$ Alan T. Tang $^{4}$. \\ Carol Gallione ${ }^{5} \cdot$ Mark L. Kahn ${ }^{4} \cdot{\text { Mark Ginsberg } \mathbb{D}^{3} \cdot \text { Douglas A. Marchuk }^{5} \cdot \text { Issam A. Awad }}^{1}$
}

Received: 9 November 2017 / Revised: 4 December 2017 / Accepted: 5 December 2017 / Published online: 26 June 2018

(c) United States \& Canadian Academy of Pathology 2018

\begin{abstract}
Cerebral cavernous malformations (CCMs) are clusters of dilated capillaries that affect around $0.5 \%$ of the population. CCMs exist in two forms, sporadic and familial. Mutations in three documented genes, KRIT1(CCM1), CCM2, and $P D C D 10(C C M 3)$, cause the autosomal dominant form of the disease, and somatic mutations in these same genes underlie lesion development in the brain. Murine models with constitutive or induced loss of respective genes have been applied to study disease pathobiology and therapeutic manipulations. We aimed to analyze the phenotypic characteristic of two main groups of models, the chronic heterozygous models with sensitizers promoting genetic instability, and the acute neonatal induced homozygous knockout model. Acute model mice harbored a higher lesion burden than chronic models, more localized in the hindbrain, and largely lacking iron deposition and inflammatory cell infiltrate. The chronic model mice showed a lower lesion burden localized throughout the brain, with significantly greater perilesional iron deposition, immune B- and T-cell infiltration, and less frequent junctional protein immunopositive endothelial cells. Lesional endothelial cells in both models expressed similar phosphorylated myosin light chain immunopositivity indicating Rho-associated protein kinase activity. These data suggest that acute models are better suited to study the initial formation of the lesion, while the chronic models better reflect lesion maturation, hemorrhage, and inflammatory response, relevant pathobiologic features of the human disease.
\end{abstract}

These author contributed equally: Hussein A. Zeineddine, Romuald Girard.

Electronic supplementary material The online version of this article (https://doi.org/10.1038/s41374-018-0030-y) contains supplementary material, which is available to authorized users.

$\triangle$ Issam A. Awad

iawad@uchicago.edu

1 Neurovascular Surgery Program, Section of Neurosurgery, The University of Chicago Medicine and Biological Sciences, Chicago, IL, USA

2 Department of Pathology, The University of Chicago Medicine and Biological Sciences, Chicago, IL, USA

3 Department of Medicine, University of California, San Diego, CA, USA

4 Department of Medicine and Cardiovascular Institute, University of Pennsylvania, Philadelphia, PA, USA

5 Molecular Genetics and Microbiology Department, Duke University Medical Center, Durham, NC, USA

\section{Introduction}

Cerebral cavernous malformation (CCM) is a common neurovascular disorder predisposing $\sim 0.5 \%$ of the population to a lifetime risk of hemorrhagic stroke, focal neurological deficits, and seizures [1-4]. The disease can arise sporadically with solitary lesions, or is inherited in an autosomal dominant pattern, with mutations affecting one of the three documented CCM genes, namely KRITI (CCM1), CCM2, and PDCD10(CCM3) [5-7]. Many studies have been published about the natural course of the disease and the lifetime risk of morbidity and mortality [4]. However, the ability to accurately predict or modify lesion behavior in the clinical setting remains problematic.

In vitro experiments and animal models examining the loss of $C C M$ gene expression have contributed significantly to our understanding of disease pathobiology [8-13]. These include activation of Rho-associated protein kinase (ROCK) [14], resulting in disrupted endothelial cell-cell junctions 
and hyper-permeability of the blood-brain barrier [10, 1517]. These are associated with repetitive hemorrhages and perilesional iron deposition, mediating clinical manifestations [18-21]. A defined B- and T-cell-mediated immune response has been reported to modulate the clinical course of the disease in human and murine models [22-24], and several studies have shown that inflammation may promote CCM development [25-28].

Mice with genetic mutations of Krit1, Ccm2, and Pdcd10 have been generated, and constitutive deletion of both copies of these genes lead to embryonic lethality, with defects in cardiac development [29-31]. Two general strategies have been used to circumvent this embryonic lethality. One approach uses mice with heterozygous $\mathrm{Ccm}$ mutations, and these develop lesions in all regions of the brain as the mice age, especially when bred in a background predisposing to somatic mutations (p53 or Msh2 gene loss) [9]. These have been referred to as "chronic models." Brains in these models recapitulate various features of the human autosomal dominant disease, including the stochastic development of new lesions over time. Lesions include primordial dilated capillaries and more mature multicavernous lesions, and they manifest other phenotypic signatures of the human disease, including increased blood-brain barrier permeability, defective endothelial cell-cell junctions, iron deposition, and immune cell infiltration $[8,9,32,33]$. These models have already been used for the preclinical testing of therapeutic agents [8, 11, 34].

CCM lesions can also be generated with great efficiency in the developing hindbrain and retinas with endothelialspecific tamoxifen-inducible Cre expression leading to homozygous loss of Krit1, Ccm2, or Pdcd10 gene in the immediate postnatal period $[14,30,32,35,36]$. In these "acute models", injection of tamoxifen in neonatal mice (at postnatal days 1-3) leads to homozygous deletion of CCM genes in endothelial cells. Lesions with similar histology as CCM develop within a few days in the hindbrain and retina, where ongoing vasculogenesis lags into the postnatal period. These animals do not typically survive into adulthood, but the models have been used very effectively to demonstrate several molecular signaling aberrations driving CCM lesion genesis [14, 37].

It remains unclear to what extent the acute models manifest the same phenotypic features as chronic lesions or the human disease. The number and volumetric lesion burden, maturation of lesions, cellular changes in lesional endothelial cells, iron deposition, and involvement of immune cells have not been studied systematically in the acute and chronical models. The potential differences will influence what aspects of disease are best modeled by each approach. Our current study aims to fill this knowledge gap by directly comparing lesion phenotypes in these two general classes of CCM murine models.

\section{Material and methods}

\section{Transgenic CCM murine models}

Six distinct Mus musculus transgenic CCM models were studied, and defined as acute (three different genotypes) or chronic (three different genotypes) models. Guidelines stated in the National Institutes of Health Guide for the Care and Use of Laboratory Animals (NIH Publications No. 8023, revised 1978) have been followed, and all animal studies have complied with the Animal Research: Reporting of In Vivo Experiments guidelines. Acute models were bred at University of Pennsylvania or the University of California at San Diego, and chronic models at Duke University. Following brain extraction and fixation, specimens were sent to a common phenotyping core laboratory at the University of Chicago for imaging and histological analyses.

\section{Cdh5 ${ }^{\text {i }}{ }^{\text {ERRT2 }}$ Krit $^{\text {ECKO }}$ acute model}

$C d h 5^{\text {CreERT2 }}$ Krit $^{f l f l}$ mice were generated by breeding Cdh5 ${ }^{\text {CreERT2 }}$ and $\mathrm{Krit}^{\mathrm{flfl}}$ mice as previously reported [14]. All mice were maintained on a mixed 129Sv/C57B16 background. At 1 day post birth, $40 \mu \mathrm{g}$ of 4hydroxytamoxifen (H7904, Sigma Aldrich, Milwaukee, WI) were dissolved in $50 \mu \mathrm{L}$ of warm $5 \%$ ethanol/corn oil vehicle (Sigma Aldrich), and were intragastrically injected into mouse pups using a 30-gauge needle. At 10 days post birth, $1 \mathrm{mg}$ of Avertin (2, 2, 2-tribromoethanol, Sigma Aldrich) was intraperitoneally injected into mouse pups for anesthesia, followed by an intracardiac perfusion of $8 \mathrm{~mL}$ of cold phosphate-buffered saline using a 27 -gauge needle. The brains were then surgically removed using a standardized procedure and dropped into a $4 \%$ paraformaldehyde fixative solution (Sigma Aldrich). The $C d h 5^{\text {CreERT2 }}$ mice were a generous gift from Ralf $\mathrm{H}$. Adams. All procedures were performed in accordance with the University of Pennsylvania Institutional Animal Care and Use Committee (IACUC) that approved all animal protocols.

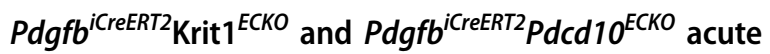 models}

The endothelial-specific conditional Kritl null mice were generated by breeding mice expressing endothelial-specific $P d g f b$ promoter driven tamoxifen-regulated Cre recombinase, CreERT2, in combination with loxP-flanked Krit1 exon $\left.5\left(P d g f b^{C r e E R T 2} K_{r i t}\right]^{f / f}\right)$ [38]. The endothelial-specific conditional $P d c d 10$ null mice were generated by breeding mice expressing $P d g f b^{C r e E R T 2}$ in combination with loxPflanked $P d c d 10$ exon $4\left(P d g f b^{C r e E R T 2} P d c d 10^{A l f l}\right)$. At 1, 2, and 3 days post birth, mice were intraperitoneally 
administered $50 \mu \mathrm{g}$ of tamoxifen (Sigma Aldrich) to induce Cre activity and endothelial Kritl or Pdcd10 gene inactivation in the littermates bearing the CreERT2. Mice were sacrificed by decapitation for phenotypic analysis on postnatal day 7. Mouse brains were surgically removed and dropped into a $10 \%$ neutral buffered formalin fixative solution (Sigma Aldrich). All animal experiments were carried out in compliance with animal procedure protocols approved by the University of California, San Diego IACUC.

\section{$\mathrm{Krit}^{+/-} \mathrm{Msh2}^{-/-}, \mathrm{Pdcd} 10^{+/-}$, and Pdcd $10^{+/-} \mathrm{Trp53}^{-/-}$ chronic models}

Animals were generated with the respective genotypes by crossing the $\mathrm{Ccm}$ heterozygous mice with mice null for Msh2 or Trp53 [9, 12, 39]. Kritl heterozygous mice do not manifest any lesions unless crossed into these backgrounds. $P d c d 10$ heterozygous mice manifest a very mild phenotype, markedly exaggerated when crossed into Msh2 or Trp53 backgrounds. Mice were sacrificed at around 4 months of age by inhalation of carbon dioxide (Airgas, Radnor Township, PA, USA) and decapitation. The mouse brains were then surgically extracted and dropped into a $10 \%$ neutral buffered formalin fixative solution (Azer Scientific, Morgantown, PA, USA). All animal protocols were approved by the Duke University IACUC, where all breeding of these models was conducted.

\section{Micro-computed tomography acquisition and lesional volumetric assessment}

Micro-computed tomography (micro-CT) imaging and volumetric assessments of lesion burden were performed using a published protocol [40]. Fixed extracted brains from the respective models were shipped to the University of Chicago, where they were processed by soaking in iodine to increase the differential contrast between CCMs and brain tissue on micro-CT images. Brains were then scanned using a transmission $180 \mathrm{kV}$ nanofocus X-ray of a Phoenix vltomelx s micro-CT system (General Electric, Fairfield, CT, USA).

The post-processing of the micro-CT-scan DICOM images and the volumetric segmentation of the iodinestained CCM lesions were performed using AMIRA 5.5.0 (FEI, Hillsboro, OR, USA). In order to correct for variations of total brain volume, the lesional to brain volume ratio was calculated.

\section{CCM mouse brain tissue processing}

Paraffin-embedded mouse brain tissue blocks of 1-mm thickness were generated at University of Chicago Human Tissue Research Center (Chicago, IL, USA). All sections were examined at $\times 1.5$ magnification for quality and presence of CCMs, using a dissecting microscope (Olympus SZ61 mounted with an Olympus DP21 camera). If a lesion was present, the block was microsectioned at $5-\mu \mathrm{m}$ thickness using a rotary microtome (Leica Biosystems Inc., Buffalo Grove, IL, USA) until a representative visualization (maximum diameter) was encountered by the histotechnicians (TM and RL). When multiple CCM lesions were encountered on the same 1-mm-thick slice, each lesion was considered individually. After hematoxylin and eosin staining, all $5-\mu \mathrm{m}$ sections were reviewed for CCMs by two independent observers (RS and TM), with findings further adjudicated by a third observer (IAA) [8, 9]. CCMs were identified and cataloged on the respective coronal tissue sections as stage 1 or stage 2. A stage $1 \mathrm{CCM}$ lesion was defined as an isolated single ballooned capillary (cavern) with a minimum diameter of $100 \mu \mathrm{m}$. Stage $2 \mathrm{CCM}$ lesions were contiguous multicavernous lesions with at least one of the caverns having a diameter of $100 \mu \mathrm{m}$ or more (Supplementary Figure 1) [8]. The lesional area was segmented by defining the borders delineating the entire CCM lesion using the polygon area function of a microscope digital camera DP21 (Olympus America Inc., Center Valley, PA, USA).

\section{Assessment of ROCK activity}

Lesional and normal brain capillary endothelial cells from chronic $\mathrm{KritI}^{+/-} \mathrm{MSh}^{-/-}$model and acute $\mathrm{Cdh} 5^{i-}$ ${ }_{\text {CrEERT2 }}$ Krit $1^{\text {ECKO }}$ model were analyzed for ROCK activity. Cells were qualitatively assessed for the intensity of phosphorylated myosin light chain and defined as either positive (stained brown) or negative (stained blue) $[8,9]$.

\section{Perls Prussian blue staining and iron quantification}

Sixteen stage 2 lesions from 13 acute Krit $^{+/-} M s h 2^{-/-}$ mice and 12 stage 2 lesions from $9 C d h 5^{\text {iCreERT2 }}$ Krit $^{\text {ECKO }}$ mice were stained using Perls Prussian blue to detect nonheme iron deposition, an index of chronic hemorrhage burden $[8,9]$. The stained tissue sections were then scanned using a $\times 20$ Zeiss objective (Zeiss Microscopy, Göttingen, Germany) mounted on a Pannoramic midi II digital slide scanner (3D Histech Ltd, Budapest, Hungary) at the Integrated Light Microscopy Facility (University of Chicago, Chicago, IL, USA), and exported as magnified TIFF images $(\times 5)$ from the digital Pannoramic Viewer (3D Histech Ltd).

The computational quantification of iron was performed using ImageJ (National Institute of Health, Bethesda, MD, USA). For each exported magnified TIFF images, a RGB color-deconvolution algorithm was applied to isolate the red, green, and blue components [41, 42]. The blue component image was then selected, inversed, and an automatic 
Rényi entropy-based thresholding method applied [43]. For each Perls Prussian blue-stained section, the cumulative intensity value was assessed based on the clusters that survived the thresholding. The cumulative intensity value was then normalized to the lesional area.

\section{Positive B- and T-lymphocyte cell staining}

Stage 2 lesions from nine $\mathrm{Kritl}^{+/-} \mathrm{Msh}^{-/-}$and five $C d h 5^{i-}$ ${ }_{\text {CreERT2 }}$ rit ${ }^{E C K O}$ mice were stained for CD45R/B220-positive $\mathrm{B}$ lymphocytes and CD3-positive $\mathrm{T}$ lymphocytes at the immunohistochemistry facility in the Human Tissue Research Center at the University of Chicago following methods previously reported $[8,9]$. Sections from spleens were also stained for CD45R/B220-positive B lymphocytes and CD3positive $\mathrm{T}$ lymphocytes, and used as positive controls.

\section{Immunofluorescent staining of tight junctional proteins}

A double-immunofluorescence labeling was performed to study the colocalization in lesions and normal vessels of cluster of differentiation 31 (CD31), a specific vascular endothelial cell protein, with the three tight junctional proteins occludin, zonula occludens 1 (ZO-1), and claudin-5. Formalin-fixed, paraffin-embedded $5 \mu \mathrm{m}$ tissue sections of brain tissues from two acute $C d h 5^{i C r e E R T 2} \mathrm{Krit}^{\mathrm{ECKO}}$ and three chronic $\mathrm{Kritl}^{+/-} \mathrm{Msh}^{-/-}$mice were deparaffinized by successive soaking in xylenes (Thermo Fisher Scientific, Waltham, MA), gradually rehydrated in ethanol (dilutions 100 , 95, 70, then 50\%, Decon Laboratories Inc., King of Prussia, PA), and transferred into deionized water. The background autofluorescence was quenched by bathing slides in $\mathrm{NH}_{4} \mathrm{CL}$ for $1 \mathrm{~h}$, followed by three washes in Tris-buffered saline (TBS, Thermo Scientific). Slides were then transferred into a pH 9 citrate buffer (Dako, Santa Clara, CA). Antigen retrieval was performed for 45 min using a steamer, cooled down for $30 \mathrm{~min}$, and then washed three times $5 \mathrm{~min}$ in TBS.

Sections were then blocked using $0.3 \%$ donkey serum for $1 \mathrm{~h}$ at room temperature. Primary antibodies were applied at optimized concentrations, as previously determined on control tissues. Endothelial cells were identified using a goat anti-mouse CD31 antibody (1/500 dilution, R\&D Systems, Minneapolis, MN). Junctional proteins were localized using rabbit anti-claudin-5 (1/1000, Novus Biologicals, Littleton, CO), rabbit anti-ZO-1 (1/1000 dilution, Thermo Scientific), or mouse monoclonal anti-occludin conjugated to Alexa Fluor 594 (1/500 dilution, Thermo Scientific) antibodies.

For dual staining of CD31/claudin-5 or CD31/ZO-1, both pairs of primary antibodies were applied overnight at $4{ }^{\circ} \mathrm{C}$. CD31 was detected with secondary antibody Alexa Fluor 594 (donkey anti-goat IgG, Jackson Immunoresearch
Laboratories West Grove, PA) and claudin-5 and ZO-1 were detected by Alexa Fluor 647 (donkey anti-rabbit IgG, Jackson Laboratories).

Dual staining of CD31/occludin was performed sequentially. The detection for each marker was completed before application of next antibody. Occludin was detected by direct labeling using the anti-occludin Alexa Fluor 594 conjugate and CD31 was detected by the Alexa Fluor 647 (donkey anti-goat, Jackson Laboratories).

Between each step, the sections were washed in TBS and $0.1 \%$ Tween 20 (Thermo Scientific) during three cycles of 5 min each. In all cases, the result of each negative control confirmed the specificity of the corresponding antibody staining.

Specimens were mounted in ProLong Gold (Thermo Fisher) antifade medium.

\section{Microscopy of the tight junctional proteins}

Z-stack images were acquired at $1.27 \mu \mathrm{m}$ intervals using a fully automated inverted wide-field Zeiss Axiover 200M microscope (Zeiss Microscopy) with a $63 \times 1.4$ numerical aperture oil immersion Hamamatsu Orca ER objective (Hamamatsu, Hamamatsu City, Japan), and deconvolved through SlideBook 6 (Intelligent Imaging Innovations Inc., Denver, CO) at the Integrated Light Microscopy Core facility (University of Chicago). The Z-stack images were exported, and the maximal intensity projection images were generated, and overlaid using ImageJ 1.5 (National Institutes of Health), and Metamorph 7.0 (Molecular Devices, Sunnyvale, CA, USA) softwares. The number of cells positive for CD31, occludin, ZO-1, and claudin-5 were then manually counted on maximal projection images.

\section{Statistical methods}

The statistical differences between the ratio of CCM lesional per brain volume, the ratio of cumulative iron intensity per lesional area in stage 2 lesions, and the number of inflammatory cells per lesional area in stage 2 lesions of two groups were assessed using an unpaired two-sample $t$ test or Wilcoxon nonparametric test when appropriate. The equality of sample variances was estimated with pooled standard deviation or Satterthwaite method.

Chi-square analyses were performed to compare the prevalence of endothelial cell ROCK activity, to assess the distribution of lesions. Chi-square method was also used to compare the difference in prevalence of lesional or normal brain capillaries endothelial cells stained with occludin, ZO1 , or claudin-5. Statistical analyses and graphics were performed, respectively, using SAS 9.4 (SAS Institute Inc., Cary, NC, USA) and GraphPad Prism 4.0 (GraphPad Software Inc., La Jolla, CA, USA). 


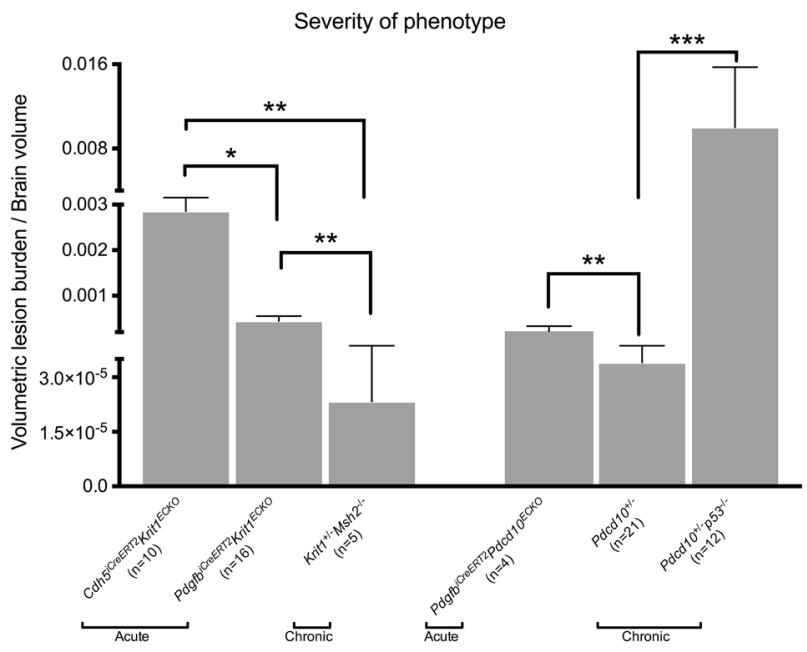

Fig. 1 Volumetric assessment of lesion burden using micro-CT. Cdh5 ${ }_{C r E E R T 2} \operatorname{Krit}^{E C K O}$ acute mice $(n=10)$ had higher adjusted volume lesion burden than the acute $P d g f b^{i C r E R T 2} K r i t 1^{E C K O}(n=16)$ and the chronic Krit ${ }^{+/-} M \operatorname{sh} 2^{-I-}(n=5) . P d c d 10^{+/-} \operatorname{Trp} 53^{-/-}$showed a significantly higher lesion burden than the non-sensitized $P d g f b^{i C r e E R T 2} P d c d 10^{E C K O}(n$ $=4)$ and $P d c d 10^{+/-}(n=21)$. All $p$ values were considered to be statistically significant at $* p<0.05, * * p<0.01$, or $* * * p<0.001$

\section{Results}

\section{Acute models harbored a higher lesion burden, mainly localized in the cerebellum, than chronic models}

The acute neonatal model $C d h 5^{\text {iCreERT2 }} \operatorname{Kritl}^{\text {ECKO }}(n=10)$ had higher adjusted volume lesion burden than the acute $P d g f b^{i C r e E R T 2} \operatorname{Krit1}^{\text {ECKO }}(n=16 ; p=0.02)$, and the chronic Kritl $^{+/-}$Msh2 $^{-/-}(n=5 ; p=0.009)$ models. Krit1 ${ }^{+/-}$Msh2 ${ }^{-/-}$harbored significantly lower lesion burden than $P d g f b^{i-}$ ${ }^{\text {CreERT2 }}$ Krit $^{\text {ECKO }}(p=0.001)$. Pdgfb ${ }^{i C r e E R T 2} P d c d 10^{E C K O}$ had significantly higher lesion burden than the chronic $P d c d 10$ ${ }^{+/-}(p=0.007)$ model. The Pdcd $10^{+/-} \operatorname{Trp} 53^{-/-}$model showed a significantly higher lesion burden than the nonsensitized $P d c d 10^{+/-}$model $(p<0.001$; Fig. 1$)$. In addition, $C d h 5^{\text {iCreERT2 }}$ Kritl $^{\text {ECKO }}$ acute model showed a predominant distribution of lesions in the cerebellum, while the chronic $\mathrm{KritI}^{+/-} \mathrm{Msh}^{-/-}$model showed a more stochastic distribution $(p<0.001)$ throughout the brain (Fig. 2).

\section{Lesions distribution}

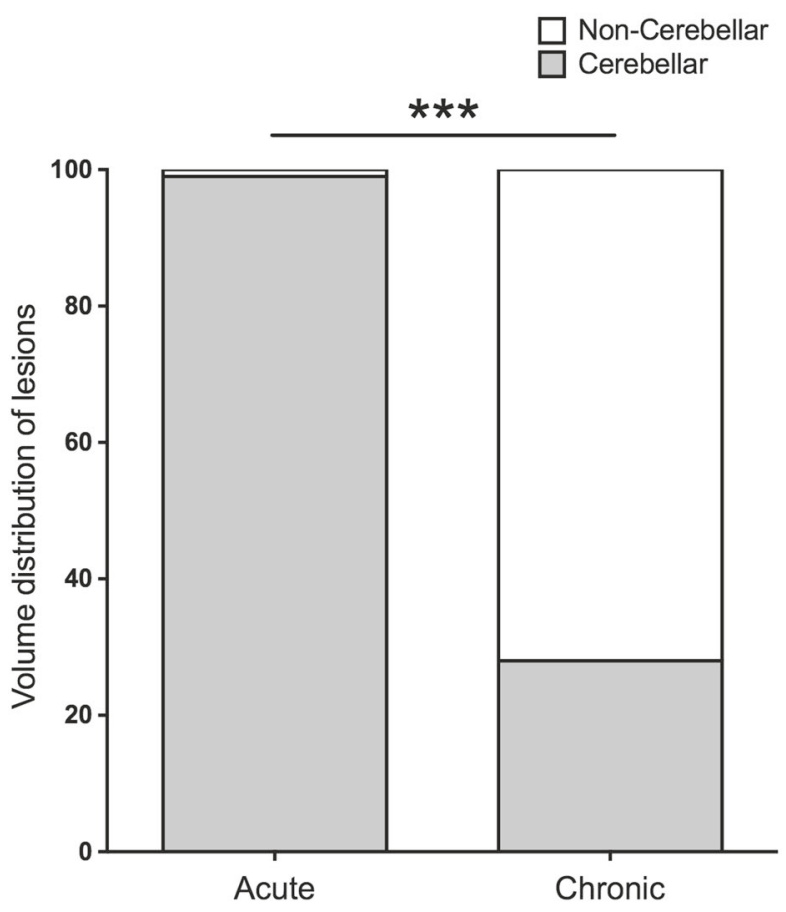

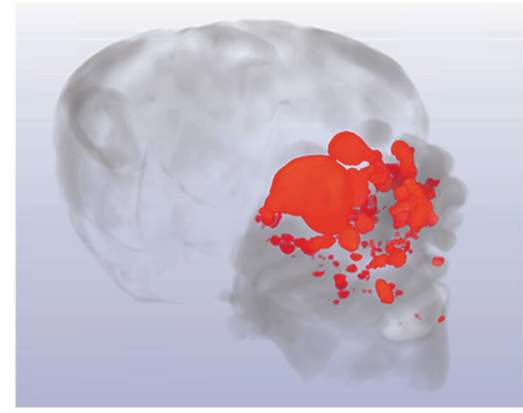

Acute

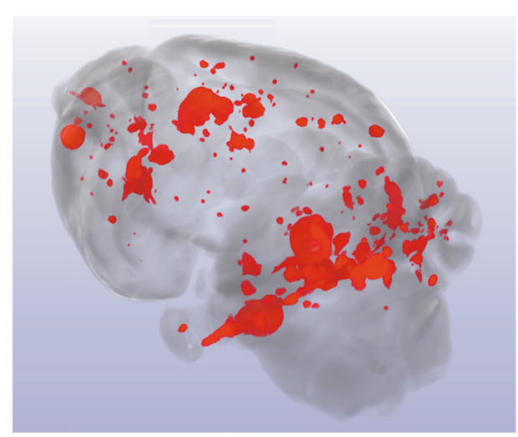

Chronic
Fig. 2 Volume distribution of lesions. Acute $C d h 5^{i \text { CreERT2 }}$ Krit $1^{\text {ECKO }}$ mice harbor proportionally more lesion within the cerebellum compared to chronic $\mathrm{Krit1}^{+/-} \mathrm{Msh}^{-/-}$mice that have a more stochastic distribution $(p<0.001)$. Example of a 3D rendering of an acute model (top) showing the highly concentrated lesion burden in the cerebellum compared to the more stochastic distribution in a chronic brain model (bottom). All $p$ values were considered to be statistically significant at $* * * p<0.001$ 


\section{Endothelial ROCK activity}

A
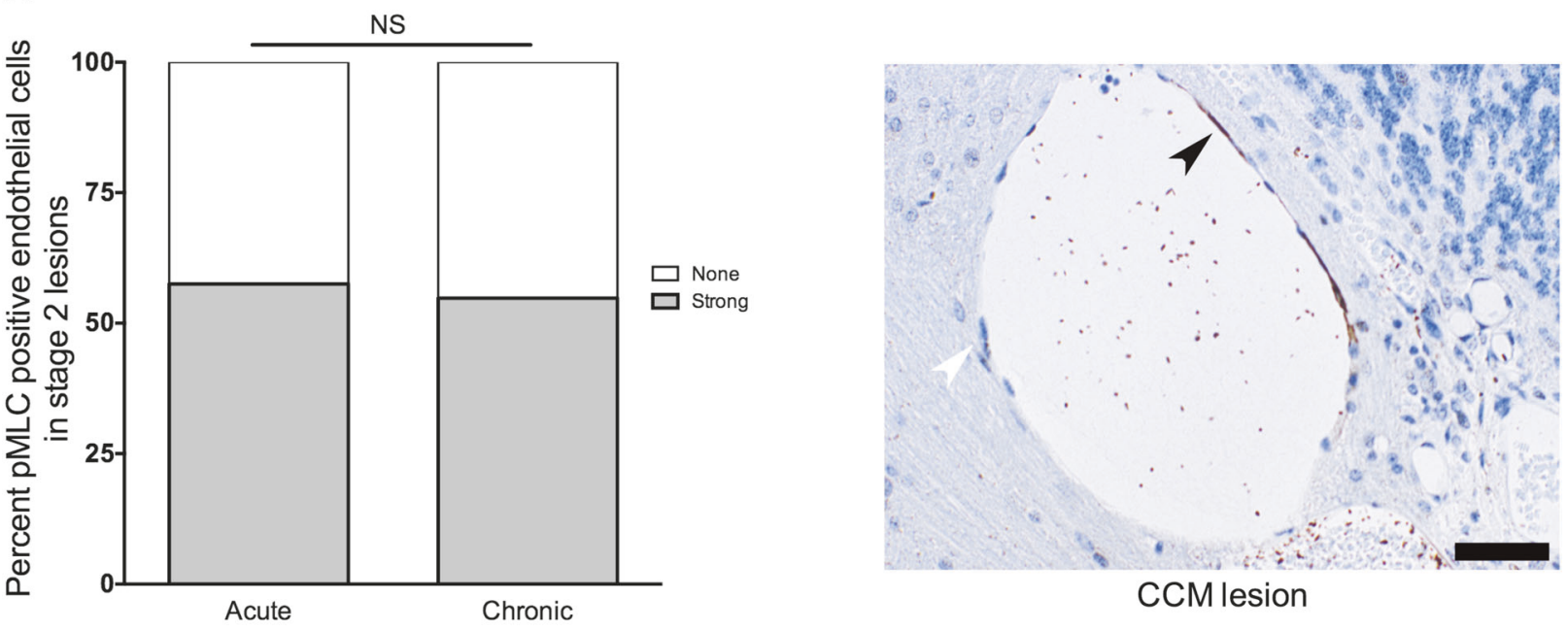

B

*
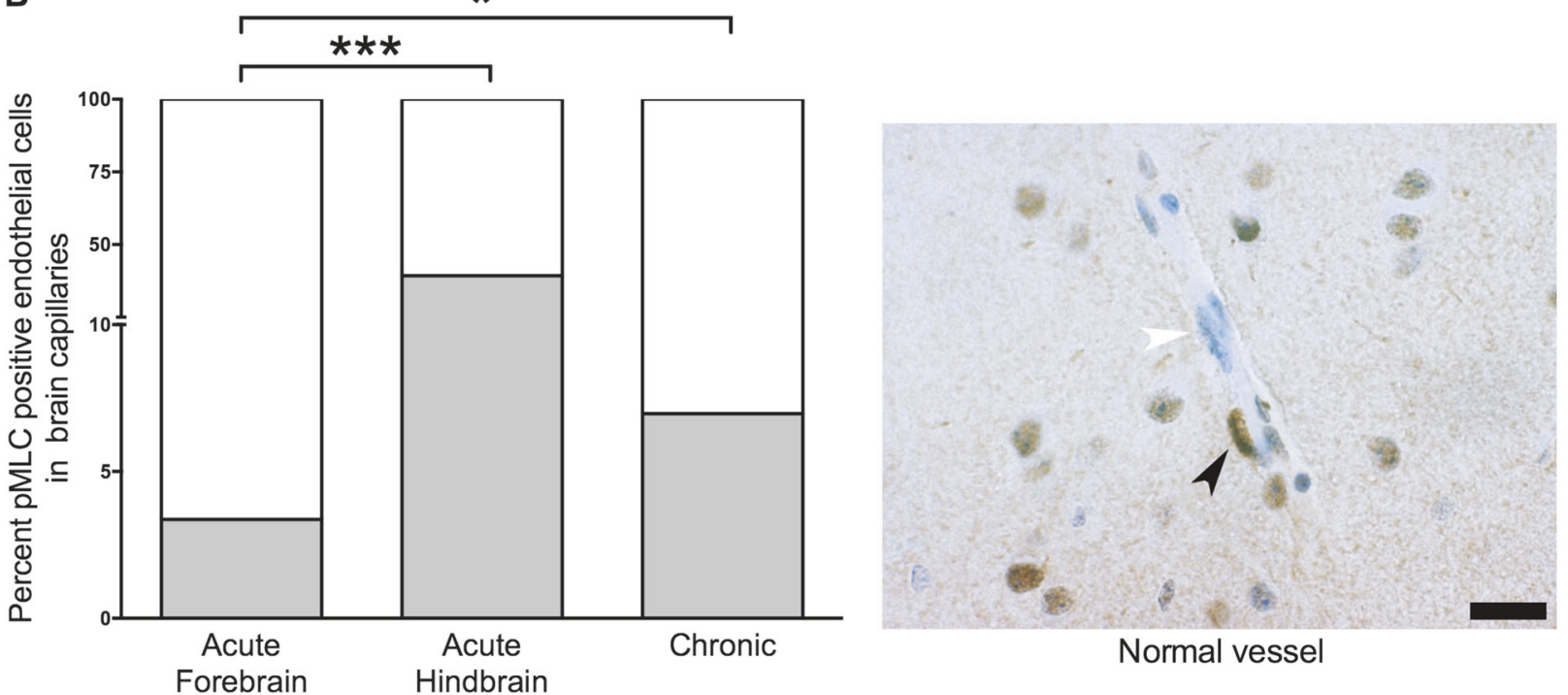

Fig. 3 Endothelial Rho kinase protein (ROCK) activity in stage 2 lesions and brain capillaries. a (Left) No significant difference was observed between the ROCK activity in endothelial cells of acute $C d h 5^{\text {iCreERT2 }} \operatorname{Krit}^{\text {ECKO }}$ ( $n=93$ cells counted in 5 lesions from 3 mice) and chronic $\mathrm{Krit}^{+/-} \mathrm{Msh}^{-/-}$lesions $(n=358$ cells counted in 13 lesions from 3 mice). (Right) Representative image of a stage 2 lesion stained for ROCK activity showing an endothelial cell with strong ROCK activity (brown staining; black arrowhead) and another with no ROCK activation (blue staining; white arrowhead). Scale bar is $50 \mu \mathrm{m}$. b (Left) $K r i t 1^{+/-} M s h 2^{-/-}$brain normal capillaries ( $n=583$ cells from

3 mice) had a significantly higher $(p=0.01)$ strong ROCK activity compared to $C d h 5^{i C r e E R T 2}$ Krit $1^{\text {ECKO }}$ normal capillaries $(n=445$ cells from 3 mice) far from lesions in the forebrain. Endothelial cells of $C d h 5^{i C r e E R T 2} \operatorname{Krit}^{\text {ECKO }}$ ( $n=179$ cells from 3 mice) normal capillaries near lesions in the hindbrain had higher strong activity $(p<0.001)$ than those far ( $n=445$ cells from 3 mice) from lesions in the forebrain. (Right) Representative image of a normal capillary stained for ROCK activity. Scale bar is $20 \mu \mathrm{m}$. All $p$ values were considered to be statistically significant at $* p<0.05$ or $* * * p<0.001$

\section{ROCK activity was differently expressed in the endothelial cells of normal capillaries in acute models and chronic models}

Lesional endothelial cells and background brain ROCK activity were assessed in acute $C d h 5^{i \text { CreERT2 }} \mathrm{Krit}^{\text {ECKO }}$ mice (13 stage 2 lesions from 3 mice) and in chronic Kritl ${ }^{+/-} \mathrm{Msh}^{-/-}$mice (5 stage 2 lesions from 3 mice). No

significant difference was observed in the ROCK activity in stage 2 lesions between acute and chronic models (Fig. 3a). However, the ROCK activity of $\mathrm{Kritl}^{+/-} \mathrm{Msh}^{-/-}$mice showed a higher prevalence of strongly stained endothelial cells in normal brain capillaries located in the forebrain compared to the acute $C d h 5^{\text {iCreERT2 }}$ Krit $1^{\text {ECKO }}$ model ( $p=$ 0.01). The endothelial cells of non-lesional brain capillaries located in the hindbrain of acute $C d h 5^{\text {iCreERT2 }}$ Krit $^{\text {ECKO }}$ 


\section{Lesional non-heme iron}

A

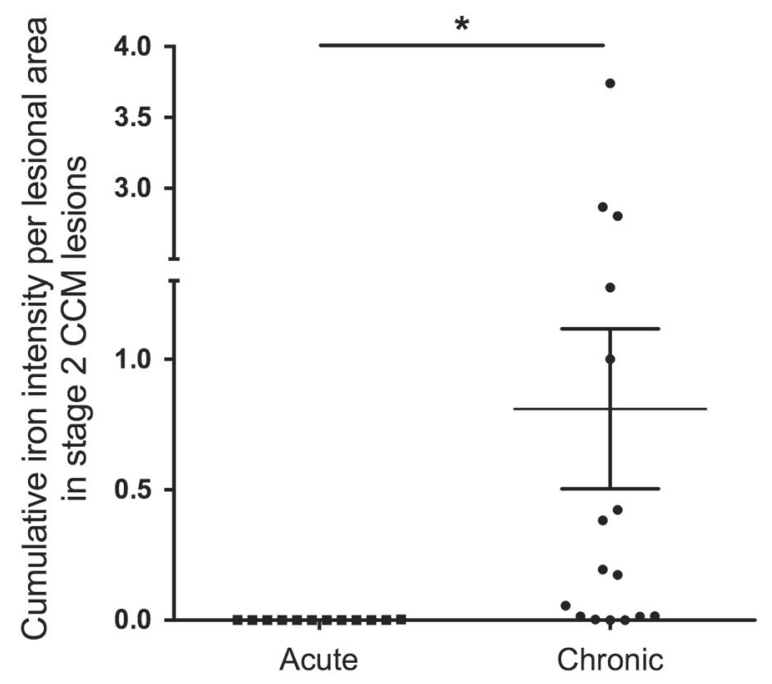

B

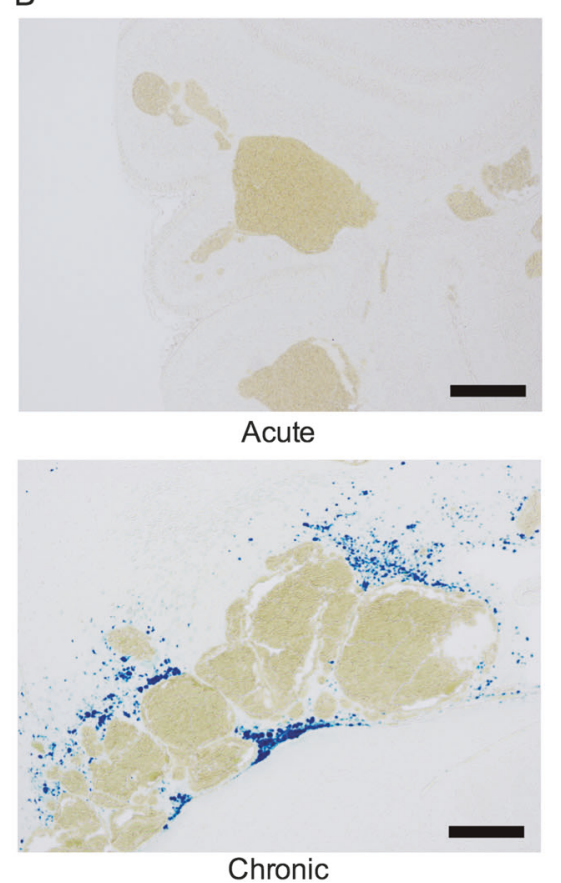

Fig. 4 Non-heme iron deposition in stage 2 CCM lesions in acute and chronic models. a Lesions from chronic Krit1 ${ }^{+l-} \mathrm{Msh}^{-1-}$ (16 lesions from 13 mice) harbor significantly higher $(p=0.03)$ integrated density of non-heme iron deposition per lesional area compared to lesions from acute $C d h 5^{i C r e E R T 2}$ Krit ${ }^{E C K O}$ (12 lesions from 9 mice). b
Representative non-heme iron deposition (Perls blue stain) in stage 2 lesions from an acute $C d h 5^{\text {iCreERT2 }}$ Krit $1^{\text {ECKO }}$ model (upper) and a chronic $C d h 5^{i C r e E R T 2}$ Krit $1^{\text {ECKO }}$ model (lower). Scale bars are $200 \mu \mathrm{m}$. All $p$ values were considered to be statistically significant at $* p<0.05$ model showed higher strong ROCK activity $(p<0.001)$ than the endothelial cells of normal brain capillaries in the forebrain (Fig. 3b).

\section{The iron deposition was higher in the stage 2 lesions of chronic models}

The stage 2 lesions of chronic Krit ${ }^{+/-} \mathrm{Msh}^{-/-}$(16 stage 2 lesions from 13 mice) showed a higher ratio of cumulative iron intensity per lesional area $(p=0.03)$ compared to the acute $C d h 5^{i C r e E R T 2}$ Krit $^{E C K O}$ (12 stage 2 lesions from 9 mice; Fig. 4).

\section{The stage 2 lesions of chronic models showed a higher number of inflammatory cells}

The chronic $\mathrm{Kritl}^{+/-} \mathrm{Msh}^{-/-}$stage 2 lesions (9 Stage 2 lesions from 9 mice) showed a higher number of B cells ( $p$ $=0.005)$ and $\mathrm{T}$ cells $(p=0.04)$ per lesional area compared to the acute $C d h 5^{i \text { CreERT2 }}$ Kritl ${ }^{\text {EKCO }}$ stage 2 lesions (14 stage 2 lesions from 5 mice; Fig. 5).

\section{The prevalence of endothelial cells expressing occludin was lower in lesions of acute and chronic models, than in non-lesional capillaries}

The prevalence of lesional endothelial cells expressing ZO1 was decreased only in chronic models compared to normal capillaries. The number of endothelial cells expressing CD31, occludin, ZO-1, and claudin-5 were assessed manually in both acute $C d h 5^{i C r e E R T 2} \operatorname{Kritl}^{E C K O}(n=2)$ and chronic Krit1 ${ }^{+-} \mathrm{Msh}^{-/-}(n=3)$ mice (Supplementary Table 1). The percentage of CD31-positive endothelial cells expressing occludin was lower in CCM lesions than in normal vessels in both acute $(p<0.0001)$ and chronic $(p=$ 0.005) models (Fig. 6a). In chronic models, the proportion of cell expressing both $\mathrm{CD} 31$ and $\mathrm{ZO}-1$ was also lower in lesions than normal vessels $(p<0.0001$; Fig. $6 \mathrm{~b})$. However, no difference was observed in the prevalence of claudin-5 immunopositive endothelial cells either between acute and chronic model lesions, or between CCM lesions and normal vessels. 
Lesional inflammatory cells infiltrates

A

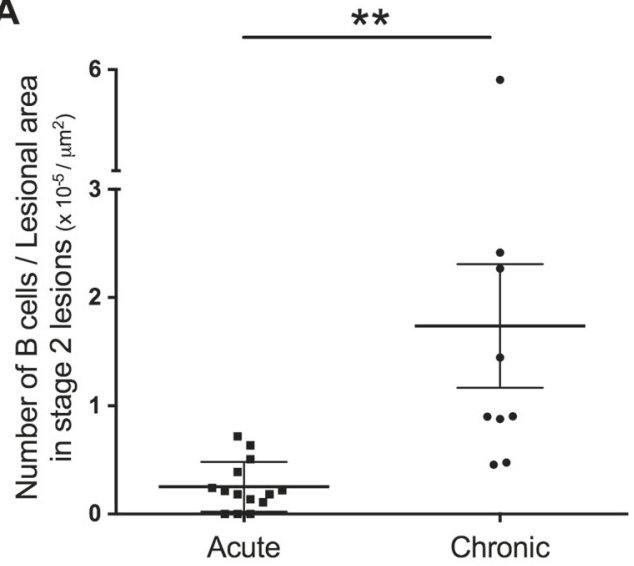

B

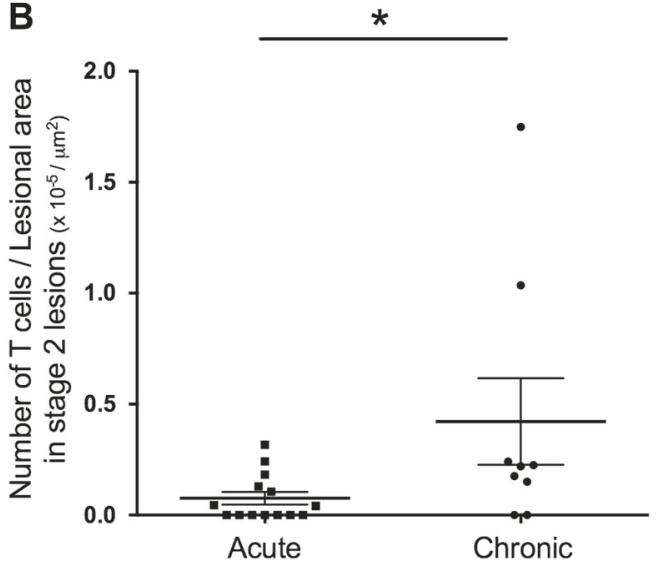

Fig. 5 Inflammatory cells in stage 2 lesions in acute and chronic CCM models. a (Left) Chronic Krit ${ }^{+/-} M s h 2^{-/-}$lesions (9 lesions from 9 mice) showed a significantly higher $(p=0.005)$ number of B cells per lesional area than the Cdh5 ${ }^{i C r e E R T 2}$ Krit $1^{\text {ECKO }}$ acute lesions (14 lesions from 5 mice). (Right) Representative image of a stage 2 showing brown stained CD45R/B220 B cells in a chronic Krit1 ${ }^{+/-} \mathrm{Msh}^{-/-}$ stage 2 lesion. b (Left) Chronic Krit1 ${ }^{+/} \mathrm{Msh}^{-/-}$lesions (9 lesions

\section{Discussion}

We herein described phenotypic differences between acute and chronic CCM mouse models, reflecting different pathogenetic features of CCM disease (Table 1). While the fundamental signaling alterations of endothelial ROCK activity and relative loss of occludin in tight junctions were present in both, many other integral pathologies, namely iron deposition and immune cell infiltration, were not observed in the acute neonatal models, nor was the endothelial loss of a second junctional protein $\mathrm{ZO}-1$.

Lesions in the heterozygous chronic models form stochastically over time, randomly distributed throughout the mouse brain, much like human lesions [44, 45]. They harbor other documented phenotypic markers of the human lesion such as iron deposition and immune cell infiltration $[9,22,23]$. Similar to the human form of the disease, there
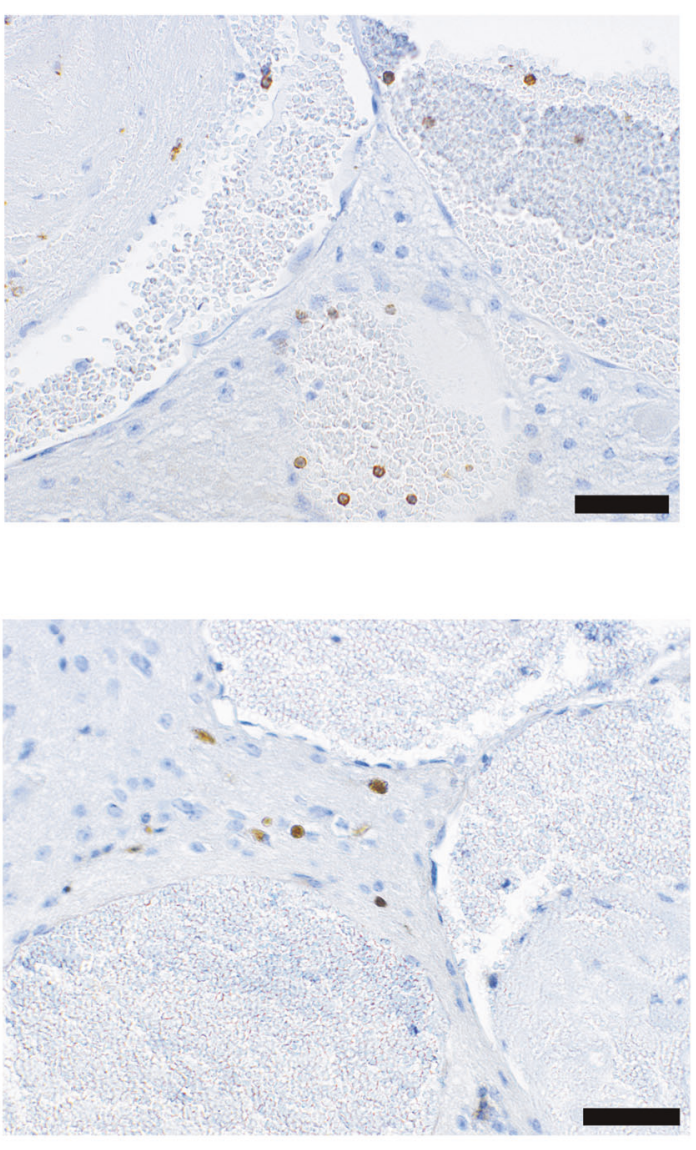

from 9 mice) showed a significantly higher $(p=0.04)$ number of $\mathrm{T}$ cells per lesional area than the $C d h 5^{i C r e E R T 2}$ Krit $1^{\text {ECKO }}$ acute lesions (14 lesions from 5 mice). (Right) Representative image of a stage 2 showing staining of CD3-positive T cells in a chronic $\mathrm{Krit}^{+/-} \mathrm{Msh} 2$ ${ }^{-/}$stage 2 lesion. Scale bars are $50 \mu \mathrm{m}$. All $p$ values were considered to be statistically significant at $* p<0.05$ or $* * p<0.01$

is a much heavier lesion burden with $P d c d 10$ mutations than with other genotypes [33, 39, 46]. Chronic models of the three $\mathrm{Ccm}$ genes $[9,47]$ have been used successfully to test the effect of various investigational drugs on lesion formation, maturation, and bleeding $[8,28]$. But these models are rather inefficient, developing a negligible lesion burden except when sensitized with complex breeding, and only one of eight mice achieving the desired genotype. Potential impact of the sensitized background ( $M s h 2$ or $T p 53$ loss) on the disease biology could not be excluded.

The acute models examined herein had much higher lesion burden than the chronic model, consistent with induced loss of gene function in angiogenically active endothelial cells in the developing hindbrain, rather than in a volume random distribution throughout the brain $[13,14,37]$. The lesion burden in acute models is likely a reflection of the efficiency and timing of the knockout as 

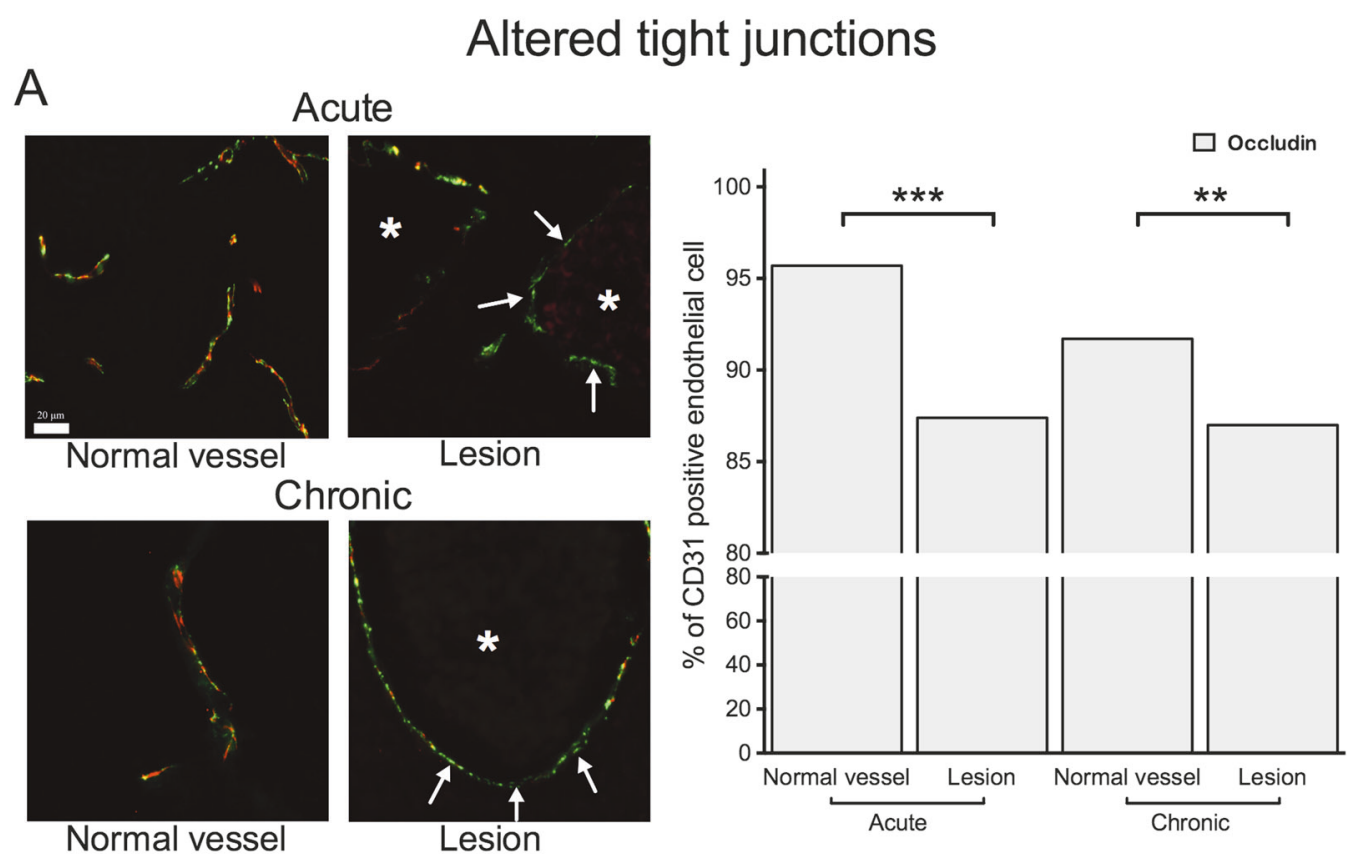

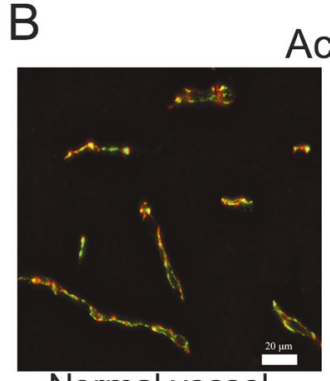

Normal vessel

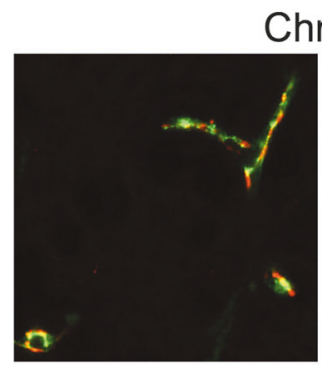

Normal vessel

Acute

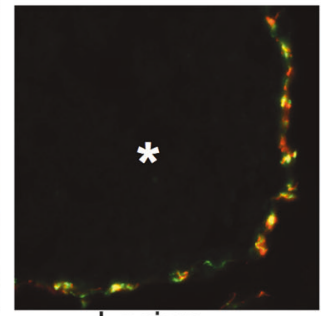

Lesion

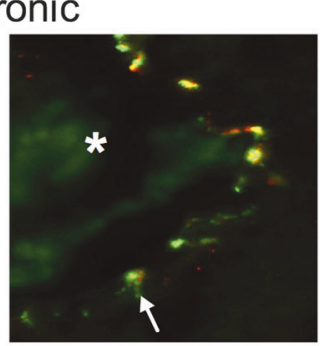

Lesion

Fig. 6 Disrupted tight junctions in acute and chronic CCM models. a The difference of CD31-positive endothelial cells (green channel) expressing occludin (red channel) and those lacking occludin was lower in CCM lesions compared to normal vessels for both acute $(p<$ $0.0001)$ and chronic $(p=0.005)$ models. b The difference of cells expressing both CD31 (green channel) and ZO-1 (red channel) and

well as the time of sacrifice of the animals. Other groups have reported models of the disease using an inducible knockout with lower lesion burdens, surviving later in life. This variability may be explained by a less-efficient knockout induction, lower aggressiveness of $\mathrm{Ccm} 2$ genotype, or the induction of gene loss later in the mouse's life $[32,33,36]$.

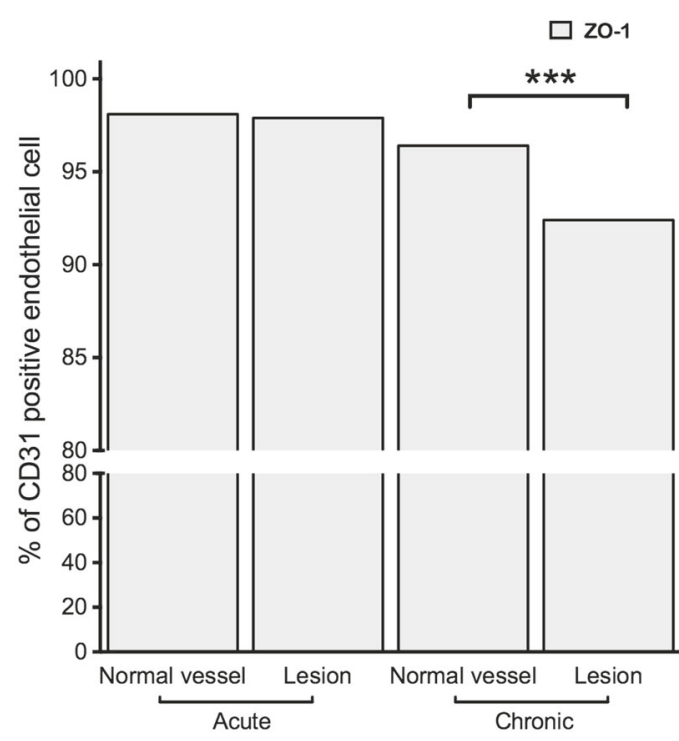

those expressing only CD31 was also lower in CCM lesions compared to normal vessels $(p<0.0001)$ only in chronic models. The white arrows indicate endothelial cell lacking junctional proteins. * indicate the lumen of the CCM lesion. Scale bars are $20 \mu \mathrm{m}$ (on the images). All $p$ values were considered to be statistically significant at $* * p<0.01$ or $* * * p<0.001$ (on the graphs)

We observed that both models had ROCK activity in a similar proportion of lesional endothelial cells. However, the chronic model background brain endothelial cells had a higher proportion of cells with increased ROCK activity. This is consistent with the heterozygous state of the chronic model in which every endothelial cell harbors only one functional gene from the time of embryogenesis. 
Table 1 Summary of phenotypic differences observed between acute and chronic CCM models compared to human

\begin{tabular}{|c|c|c|c|}
\hline & Acute murine & Chronic murine & Human \\
\hline Genotype & 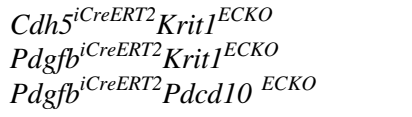 & $\begin{array}{l}\operatorname{Krit}^{+/-} \mathrm{Msh}^{-/-} \\
\operatorname{Pdcd}_{10^{+-}-} \\
\operatorname{Pdcd}_{10^{+/-}} \operatorname{Trp}^{-1-}\end{array}$ & $\begin{array}{l}\text { KRIT1 } 1^{+/-} \\
C C M 2^{+/-} \\
P D C D 10^{+/-}\end{array}$ \\
\hline $\begin{array}{l}\text { Lesion burden and } \\
\text { distribution (Figs. } 1 \\
\text { and 2) }\end{array}$ & $\begin{array}{l}\text { - Higher lesion burden than } \\
\text { chronic models } \\
\text { - Localized in the cerebellum } \\
\text { - More aggressive in Pdcd10 } \\
\text { genotype }\end{array}$ & $\begin{array}{l}\text { - Lower lesion burden than acute } \\
\text { models } \\
\text { - Random brain volume distribution } \\
\text { - More aggressive in } P d c d 10 \\
\text { genotype }\end{array}$ & $\begin{array}{l}\text { - Lesion burden depends on the genotype, } \\
\text { greater with PDCD10 [39] } \\
\text { - Random brain volume distribution in familial } \\
\text { cases; near developmental venous anomalies in } \\
\text { sporadic cases [45] }\end{array}$ \\
\hline $\begin{array}{l}\text { ROCK activity in } \\
\text { ECs (Fig. 3) }\end{array}$ & $\begin{array}{l}\text { - Robust in lesional ECs, present } \\
\text { in hindbrain normal capillaries }\end{array}$ & $\begin{array}{l}\text { - Robust in lesional ECs, present in } \\
\text { normal capillaries throughout the } \\
\text { brain }\end{array}$ & $\begin{array}{l}\text { - Robust in lesional ECs, present in normal } \\
\text { brain capillaries in familial cases [39] }\end{array}$ \\
\hline $\begin{array}{l}\text { Lesional non-heme } \\
\text { iron deposition }{ }^{\mathrm{a}} \\
\text { (Fig. 4) }\end{array}$ & - Minimal in stage 2 lesions & - Robust in stage 2 lesions & - Robust in CCM lesions [18] \\
\hline $\begin{array}{l}\text { Infiltrated } \\
\text { inflammatory cells (B } \\
\text { and T cells) })^{\text {a }} \text { (Fig. 5) }\end{array}$ & - Minimal in stage 2 lesions & - Robust in stage 2 lesions & - Robust in CCM lesions [23] \\
\hline $\begin{array}{l}\text { Tight junctions } \\
\text { (Fig. 6) }\end{array}$ & $\begin{array}{l}\text { - Lower prevalence of lesional } \\
\text { ECs expressing occludin } \\
\text { compared to normal ECs }\end{array}$ & $\begin{array}{l}\text { - Lower prevalence of lesional ECs } \\
\text { expressing occludin and ZO-1 } \\
\text { compared to normal ECs }\end{array}$ & $\begin{array}{l}- \text { Lower expression of claudin-5, occludin and } \\
\text { ZO-1 on lesional ECs compared to normal ECs } \\
{[50]}\end{array}$ \\
\hline
\end{tabular}

$C C M$ cerebral cavernous malformation, $E C s$ endothelial cells, $Z O-1$ zona occludens-1

${ }^{a}$ Relative to lesional area

Conversely, ROCK activity in normal capillary endothelium was increased in the hindbrain but not forebrain of acute models, consistent with the loss of $\mathrm{Ccm}$ gene function in these regions of the brain with angiogenic activity. Staining for $\mathrm{Ccm}$ proteins was not performed in these experiments, but this is currently being pursued in a larger project, looking at clonal vs. mosaic loss of gene function and deterministic lesion development.

Lesions from acute models showed minimal iron deposition consistent with the absence of chronic hemorrhage. This may be related to the early sacrifice of these animals secondary to the high lesion burden. Other models of inducible knockout where animals survived later in life did in fact show some iron deposition in the older animals $[33,36,48]$. We also described a limited inflammatory response in acute lesions. This may be explained by an immature neonatal immune system [49], or by the immune response potentially developing over time, or in reaction to chronic hemorrhage. Hence, signaling and molecular alterations related to bleeding and inflammation might thus be either underrepresented or missing altogether in the acute models. Interventions targeting chronic bleeding and inflammatory mechanisms influencing lesion development cannot be tested, and novel targets of therapy may be missed by solely relying on these neonatal models. This is particularly cogent with the recent evidence of the potential role of immune-modulation as CCM therapy [26], and the impact of statins on iron deposition in CCM [28].
We observed a lower proportion of endothelial cells expressing occludin immunopositivity in the lining of lesions of both acute and chronic models in comparison to non-lesional capillary endothelium. We also found a lower proportion of lesional endothelial cells with ZO-1 expression in chronic models. The mRNA expression of occludin, claudin-5, and ZO-1 has been reported to be downregulated in resected human CCM lesion [50]. ROCK mediates the formation of the tight junctions by phosphorylating occludin and claudins to regulate permeability through endothelial cell monolayers $[10,51,52]$. In vitro and in vivo studies demonstrated that pro-inflammatory processes downregulate the expression of ZO-1, and increase blood-brain barrier permeability [53-56]. Our collaborators reported a loss of ZO-1 expression with Krit1 loss in cultured brain microvascular endothelial cells [57]. The results herein demonstrate a gross disruption of junctional protein expression in a fraction of endothelial cells lining CCM lesions in murine brains. The loss of tight junction proteins is more overt in chronic lesions, involving both occludin and ZO-1, perhaps reflecting a process of lesion maturation.

Overall, we describe a number of key phenotypic differences between acute and chronic models. Acute models will remain highly valuable, with advantages of efficient and quick lesion development, allowing the characterization of fundamental signaling aberrations driving CCM lesion formation. Conversely, chronic models are less efficient at developing lesions, but reflect more faithfully other features 
of lesion maturation, including chronic hemorrhage and inflammation, and stochastic lesion development over time. They allow more reliable testing of therapies targeting these clinically relevant features of the human disease.

Chronic models develop stage 1 and stage 2 lesions stochastically over time, hence using them at an earlier age would not yield significant lesion burden for meaningful study. Conversely, acute models (except with the milder Ccm2 genotype) do not typically survive into adulthood or are very ill in view of severity of hindbrain lesion burden. We foresee the development of new hybrid models, seeking to induce gene loss less efficiently, or later postnatally. This could create a burden of lesions that increases stochastically over time, and allows lesions to develop mature features of chronic hemorrhage and inflammation, potentially recapitulating advantages of both models.

Acknowledgements This work was supported, in part, by grants from the National Institute of Neurological Disorders and Stroke (P01 NS092521 to MLK, MG, DAM, and IAA, and F30 NS100252 to ATT) and from the National Center for Advancing Translational Sciences of the National Institutes of Health (UL1 TR000430), and by the University of Chicago Medicine Comprehensive Cancer Center Support Grant (P30 CA14599) including services provided by the Immunohistochemistry and Integrated Microscopy core facilities. RG received support from by the William and Judith Davis Fund in Neurovascular Surgery Research, and by the Safadi Translational Fellowship at the University of Chicago. Funding sources played no role in the formulation of research questions nor the interpretation of results.

\section{Compliance with ethical standards}

Conflict of interest The authors declare that they have no conflict of interest.

\section{References}

1. Abdulrauf SI, Kaynar MY, Awad IA. A comparison of the clinical profile of cavernous malformations with and without associated venous malformations. Neurosurgery. 1999;44:41-6.

2. Vernooij MW, Ikram MA, Tanghe HL, et al. Incidental findings on brain MRI in the general population. $\mathrm{N}$ Engl $\mathrm{J}$ Med. 2007;357:1821-8.

3. Al-Shahi Salman R, Berg MJ, Morrison L, et al. Hemorrhage from cavernous malformations of the brain: definition and reporting standards. Angioma Alliance Scientific Advisory Board. Stroke. 2008;39:3222-30.

4. Al-Shahi Salman R, Hall JM, Horne MA, et al. Untreated clinical course of cerebral cavernous malformations: a prospective, population-based cohort study. Lancet Neurol. 2012;11:217-24.

5. Bergametti F, Denier C, Labauge P, et al. Mutations within the programmed cell death 10 gene cause cerebral cavernous malformations. Am J Hum Genet. 2005;76:42-51.

6. Liquori CL, Berg MJ, Squitieri F, et al. Deletions in CCM2 are a common cause of cerebral cavernous malformations. Am J Hum Genet. 2007;80:69-75.

7. Stahl S, Gaetzner S, Voss K, et al. Novel CCM1, CCM2, and CCM3 mutations in patients with cerebral cavernous malformations: in-frame deletion in CCM2 prevents formation of a CCM1/CCM2/CCM3 protein complex. Hum Mutat. 2008;29:709-17.

8. McDonald DA, Shi C, Shenkar R, et al. Fasudil decreases lesion burden in a murine model of cerebral cavernous malformation disease. Stroke. 2012;43:571-4.

9. McDonald DA, Shenkar R, Shi C, et al. A novel mouse model of cerebral cavernous malformations based on the two-hit mutation hypothesis recapitulates the human disease. Hum Mol Genet. 2011;20:211-22.

10. Stockton RA, Shenkar R, Awad IA, et al. Cerebral cavernous malformations proteins inhibit Rho kinase to stabilize vascular integrity. J Exp Med. 2010;207:881-96.

11. Chan AC, Li DY, Berg MJ, et al. Recent insights into cerebral cavernous malformations: animal models of CCM and the human phenotype. FEBS J. 2010;277:1076-83.

12. Plummer NW, Gallione CJ, Srinivasan S, et al. Loss of p53 sensitizes mice with a mutation in Ccm1 (KRIT1) to development of cerebral vascular malformations. Am J Pathol. 2004;165:1509-18.

13. Maddaluno L, Rudini N, Cuttano R, et al. EndMT contributes to the onset and progression of cerebral cavernous malformations. Nature. 2013;498:492-6.

14. Zhou Z, Tang AT, Wong WY, et al. Cerebral cavernous malformations arise from endothelial gain of MEKK3-KLF2/4 signalling. Nature. 2016;532:122-6.

15. Richardson BT, Dibble CF, Borikova AL, et al. Cerebral cavernous malformation is a vascular disease associated with activated RhoA signaling. Biol Chem. 2013;394:35-42.

16. Borikova AL, Dibble CF, Sciaky N, et al. Rho kinase inhibition rescues the endothelial cell cerebral cavernous malformation phenotype. J Biol Chem. 2010;285:11760-4.

17. Mikati AG, Tan H, Shenkar R, et al. Dynamic permeability and quantitative susceptibility: related imaging biomarkers in cerebral cavernous malformations. Stroke. 2014;45:598-601.

18. Tan H, Liu T, Wu Y, et al. Evaluation of iron content in human cerebral cavernous malformation using quantitative susceptibility mapping. Invest Radiol. 2014;49:498-504.

19. Tan H, Zhang L, Mikati AG, et al. Quantitative susceptibility mapping in cerebral cavernous malformations: clinical correlations. AJNR Am J Neuroradiol. 2016;37:1209-15.

20. Baumann CR, Schuknecht B, Lo Russo G, et al. Seizure outcome after resection of cavernous malformations is better when surrounding hemosiderin-stained brain also is removed. Epilepsia. 2006;47:563-6.

21. Girard R, Fam MD, Zeineddine HA, et al. Vascular permeability and iron deposition biomarkers in longitudinal follow-up of cerebral cavernous malformations. J Neurosurg. 2017;127: $102-10$.

22. Shi C, Shenkar R, Kinloch A, et al. Immune complex formation and in situ B-cell clonal expansion in human cerebral cavernous malformations. J Neuroimmunol. 2014;272:67-75.

23. Shi C, Shenkar R, Du H, et al. Immune response in human cerebral cavernous malformations. Stroke. 2009;40:1659-65.

24. Girard R, Zeineddine HA, Fam MD. et al. Plasma biomarkers of inflammation reflect seizures and hemorrhagic activity of cerebral cavernous malformations. Transl Stroke Res. 2018;9: 34-43.

25. Li DY, Whitehead KJ. Evaluating strategies for the treatment of cerebral cavernous malformations. Stroke. 2010;41:S92-94.

26. Shi C, Shenkar R, Zeineddine HA, et al. B-cell depletion reduces the maturation of cerebral cavernous malformations in murine models. J Neuroimmune Pharmacol. 2016;11:369-77.

27. Retta SF, Glading AJ. Oxidative stress and inflammation in cerebral cavernous malformation disease pathogenesis: two sides of the same coin. Int J Biochem Cell Biol. 2016;81:254-70. 
28. Shenkar R, Shi C, Austin C, et al. RhoA kinase inhibition with fasudil versus simvastatin in murine models of cerebral cavernous malformations. Stroke. 2017;48:187-94.

29. Whitehead KJ, Plummer NW, Adams JA, et al. Ccm1 is required for arterial morphogenesis: implications for the etiology of human cavernous malformations. Development. 2004;131: $1437-48$.

30. Whitehead KJ, Chan AC, Navankasattusas S, et al. The cerebral cavernous malformation signaling pathway promotes vascular integrity via Rho GTPases. Nat Med. 2009;15:177-84.

31. He Y, Zhang H, Yu L, et al. Stabilization of VEGFR2 signaling by cerebral cavernous malformation 3 is critical for vascular development. Sci Signal. 2010;3:ra26 http://stke.sciencemag.org/ content/3/116/ra26.long

32. Boulday G, Rudini N, Maddaluno L, et al. Developmental timing of CCM2 loss influences cerebral cavernous malformations in mice. J Exp Med. 2011;208:1835-47.

33. Chan AC, Drakos SG, Ruiz OE, et al. Mutations in 2 distinct genetic pathways result in cerebral cavernous malformations in mice. J Clin Invest. 2011;121:1871-81.

34. Girard R, Khanna O, Shenkar R, et al. Peripheral plasma vitamin D and Non-HDL cholesterol reflect the severity of cerebral cavernous malformation disease. Biomark Med. 2016;10: 255-64.

35. Boulday G, Blecon A, Petit N, et al. Tissue-specific conditional CCM2 knockout mice establish the essential role of endothelial CCM2 in angiogenesis: implications for human cerebral cavernous malformations. Dis Model Mech. 2009;2:168-77.

36. Cunningham K, Uchida Y, O'Donnell E, et al. Conditional deletion of $\mathrm{Ccm} 2$ causes hemorrhage in the adult brain: a mouse model of human cerebral cavernous malformations. Hum Mol Genet. 2011;20:3198-206.

37. Tang AT, Choi JP, Kotzin JJ, et al. Endothelial TLR4 and the microbiome drive cerebral cavernous malformations. Nature. 2017;545:305-10.

38. Claxton S, Kostourou V, Jadeja S, et al. Efficient, inducible Crerecombinase activation in vascular endothelium. Genesis. 2008;46:74-80.

39. Shenkar R, Shi C, Rebeiz T, et al. Exceptional aggressiveness of cerebral cavernous malformation disease associated with PDCD10 mutations. Genet Med. 2015;17:188-96.

40. Girard R, Zeineddine HA, Orsbon C, et al. Micro-computed tomography in murine models of cerebral cavernous malformations as a paradigm for brain disease. J Neurosci Methods. 2016;271:14-24.

41. Ruifrok AC. Quantification of immunohistochemical staining by color translation and automated thresholding. Anal Quant Cytol Histol. 1997;19:107-13.

42. Ruifrok AC, Katz RL, Johnston DA. Comparison of quantification of histochemical staining by hue-saturation-intensity (HSI) transformation and color-deconvolution. Appl Immunohistochem Mol Morphol. 2003;11:85-91.

43. Sahoo P, Wilkins C, Yeager J. Threshold selection using Renyi's entropy. Pattern Recognit. 1997;30:71-84.

44. Shenkar R, Venkatasubramanian PN, Wyrwicz AM, et al. Advanced magnetic resonance imaging of cerebral cavernous malformations: part II. Imaging of lesions in murine models. Neurosurgery. 2008;63:790-8.

45. Batra S, Lin D, Recinos PF, et al. Cavernous malformations: natural history, diagnosis and treatment. Nat Rev Neurol. 2009;5:659-70.

46. Denier C, Labauge P, Bergametti F, et al. Genotype-phenotype correlations in cerebral cavernous malformations patients. Ann Neurol. 2006;60:550-6.

47. Akers AL, Johnson E, Steinberg GK, et al. Biallelic somatic and germline mutations in cerebral cavernous malformations (CCMs): evidence for a two-hit mechanism of CCM pathogenesis. Hum Mol Genet. 2009;18:919-30.

48. Mleynek TM, Chan AC, Redd M, et al. Lack of CCM1 induces hypersprouting and impairs response to flow. Hum Mol Genet. 2014;23:6223-34.

49. Adkins B, Leclerc C, Marshall-Clarke S. Neonatal adaptive immunity comes of age. Nat Rev Immunol. 2004;4:553-64.

50. Schneider $\mathrm{H}$, Errede $\mathrm{M}$, Ulrich $\mathrm{NH}$, et al. Impairment of tight junctions and glucose transport in endothelial cells of human cerebral cavernous malformations. J Neuropathol Exp Neurol. 2011;70:417-29.

51. Yamamoto M, Ramirez SH, Sato S, et al. Phosphorylation of claudin-5 and occludin by rho kinase in brain endothelial cells. Am J Pathol. 2008;172:521-33.

52. Bond LM, Sellers JR, McKerracher L. Rho kinase as a target for cerebral vascular disorders. Future Med Chem. 2015;7:1039-53.

53. da Fonseca AC, Matias D, Garcia C, et al. The impact of microglial activation on blood-brain barrier in brain diseases. Front Cell Neurosci. 2014;8:362. https://doi.org/10.3389/ fncel.2014.00362.

54. Elahy M, Jackaman C, Mamo JC, et al. Blood-brain barrier dysfunction developed during normal aging is associated with inflammation and loss of tight junctions but not with leukocyte recruitment. Immun Ageing. 2015;12:2. https://doi.org/10.1186/ s12979-015-0029-9.

55. Lopez-Ramirez MA, Fischer R, Torres-Badillo CC, et al. Role of caspases in cytokine-induced barrier breakdown in human brain endothelial cells. J Immunol. 2012;189:3130-9.

56. Lopez-Ramirez MA, Wu D, Pryce G, et al. MicroRNA-155 negatively affects blood-brain barrier function during neuroinflammation. FASEB J. 2014;28:2551-65.

57. Lopez-Ramirez MA, Fonseca G, Zeineddine HA, et al. Thrombospondin1 (TSP1) replacement prevents cerebral cavernous malformations. J Exp Med. 2017;214:3331-46. 